\title{
Use of new oral anticoagulants secondary to Paget-Schroetter syndrome in a young sportsman: A case report
}

\author{
Kenan Abdurrahman Kara ${ }^{1}$, Uğur Diliçıkık², Başar Sarıkaya ${ }^{3}$, Şenol Gülmen ${ }^{4}$
}

\footnotetext{
1) Hisar Intercontinental Hospital, Cardiovascular Surgery Department, Op.Dr., Istanbul, Turkey

2) Kanuni Sultan Süleyman Training and Research Hospital, Department of Sports Medicine, MD., Istanbul, Turkey

3) Yeditepe University, Department of Radiology, Assoc.Prof., Istanbul, Turkey

${ }^{4)}$ Süleyman Demirel University Faculty of Medicine, Department of Cardiovascular Surgery, Assoc. Prof.Dr., Isparta, Turkey
}

\section{Introduction}

Introduction: The Paget-Schroetter syndrome or "effort thrombosis" is a deep venous thrombosis of subclavian-axillar vein at the costoclavicular junction. It affects predominately young and athletic people with an inherent anatomic variant at the costoclavicular junction that triggers the formation of a primary thrombosis. It is important to identify this syn-drome in order to prevent further complications, such as post-thrombotic syndrome, pulmonary embolism (PE), or even death. We present a clinical case in which a young professional basketball player developed a subclavian venous thrombosis and was managed with new oral anticoagulant.

Keyword: Oral anticoagulants, effort thrombosis, Paget-Schroetter syndrome, sportsman 


\section{Case Report}

We describe a case of a 17-year-old male, Turkish basketball player, who presented to the clinic with one-week course of left upper limb pain with swelling and mild erythema. There was no previous history of chest trauma and patient denied having fever. The patient had no known medical problems, no medications and no prior family history of hematologic-related diseases. On physical examination his blood pressure was $116 / 88 \mathrm{mmHg}$, pulse rate $88 / \mathrm{min}$, pulse oximetry showed $94 \%$ on room air, temperature was $36.4^{\circ} \mathrm{C}$. His lungs were clear on auscultation and his heart sounds were normal. Edema, tenderness and erythema were found over the left upper extremity, peripheral arterial pulses were clear with palpation and no motor or sensitive deficit was present. The patient had also Urschel's sign, characterized by the dilation of veins that can be visible across the shoulder and upper arm. ${ }^{(1,2)}$

An upper extremity venous Doppler ultrasound study was performed which confirmed the presence of a par-tially occlusive deep vein thrombosis in the left subclavian vein. HematologyInvestigations, including complete blood count, coagulation studies, and renal function tests, yielded normal results. Work-up for thrombophilic disorders includ-ed homocysteine, protein $\mathrm{C}$, antithrombin III, and anti-cardiolipin antibody levels which were all within the normal range. In the ED, the patient was then placed on Pradaxa (dabigatran) $150 \mathrm{mg}$ orally daily

\section{Discussion}

Primary axillary-subclavian vein thrombosis, first described by Paget in 1875 and Schroetter in 1884, was named Paget-Schroetter syndrome (PSS) by Hughes in 1948. (7) Upper extremity effort thrombosis accounts for approximately $1-4 \%$ of all episodes of venous thrombosis. ${ }^{(2)}$ PSS most often develops among young adults who work in occupations that require repeated arm movements which cause axillo-subclavian vein trauma and facilitate the development of deep vein thrombosis (DVT). ${ }^{(8)}$ Several sporting activities have been associated with axillary vein thrombosis, including ball games, racket games, and aquatic sports. Due to repeti-

\section{Figure 1.}

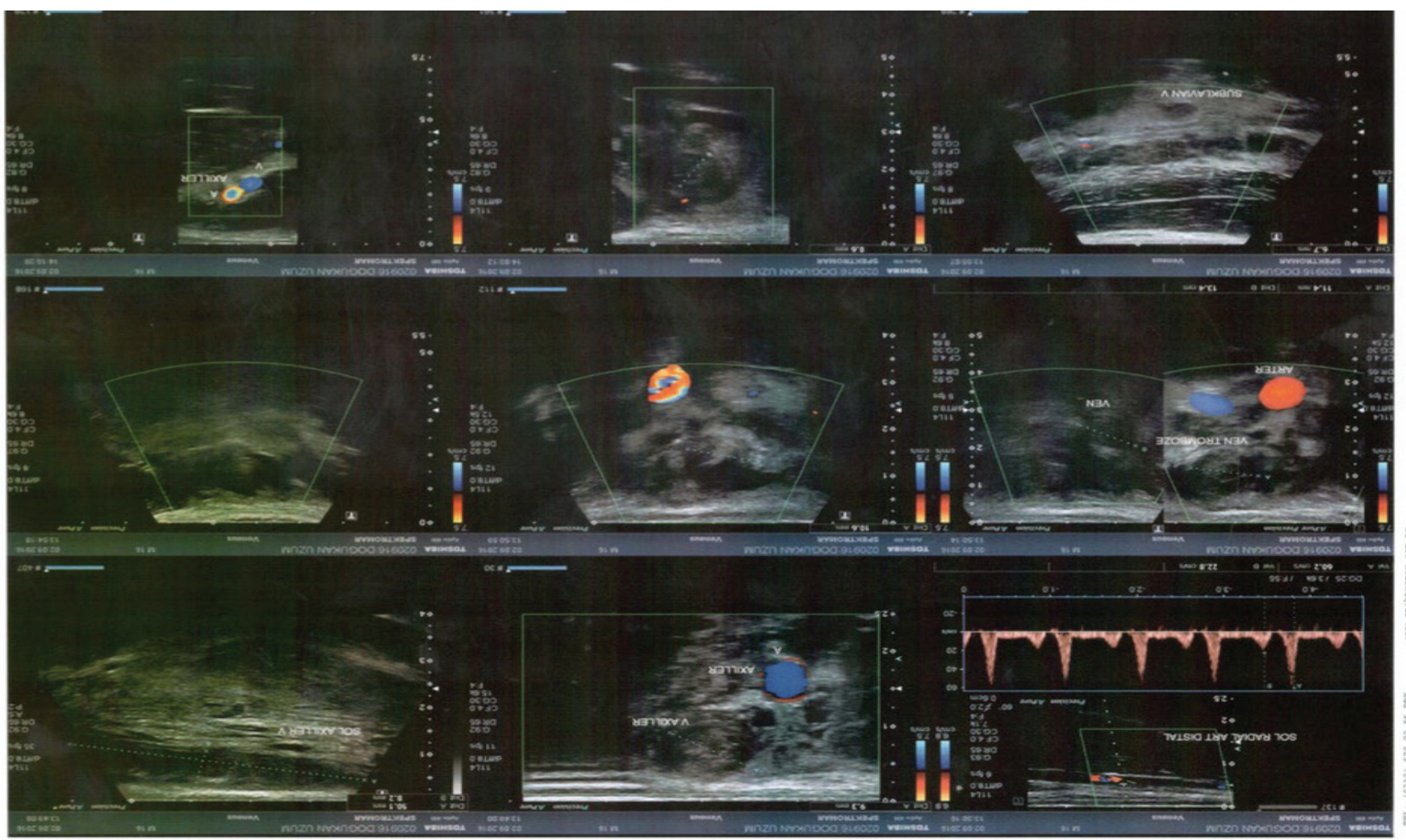


tive extension and hyperabduction movements of the upper limb, this kind of thrombosis is known as effort thrombosis. ${ }^{(9)}$ Hematologic, anatomic, and iatrogenic predisposing factors such as thrombophilia, thorasic outlet syndrome (TOS), and major vein catheterisation are typically underlying conditions. ${ }^{(10-13)}$ Clinical features of PSS include sudden onset of pain, swelling, edema, and cyanosis of the upper limb. Collateral veins are evident around the shoulder and chest. The pain increases with exercise and decreases with rest and elevation of the affected extremity. ${ }^{(14)}$

Two theories explain the initial process that generates the final event of thrombosis in the Paget-Schroetter syndrome. The first one has been involved in a frequent activity of the arm followed by the development of a hypertrophy in the anterior scalene muscle; this, leading to blood stasis and clot formation. Secondly, several descriptions suggest that secondary thrombosis begins with a structural compression (abnormalities in the thoracic outlet), which triggers a con-tinuous process of fibrosis and scaring in the external environment surrounding the subclavian vein, of an exchange of the collagen fibers from loose connective tissue to a dense collagen scar. These perpetuate the process of stasis and thrombosis. ${ }^{(3)}$

The typical clinical presentation is a sudden onset pain, heaviness, blue-red discoloration and swelling of the upper affected arm. However, due to the mainly presentation in young athletic patients, the syndrome tends to be asymptomatic, or described by the patient as a simple muscular strain. In patients with intermittent obstruction, the symptoms will appear and disappear according to the process of obstruction. Occasionally, patients present the "Urschel's sign", characterized by the dilation of veins that can be visible across the shoulder and upper arm..$^{(2)}$

The mainstream treatment of upper extremity throm- bosis is based on the correction of the underlying defect and pre-vents future episodes. Currently, the gold standard in the management of this unusual thrombosis is the thrombolytic therapy. Catheter-directed thrombolysis has reported a successful of $62-82 \%$, being higher in recent fresh clots (symp-toms $<2-6$ weeks) followed by a venoplasty if there is evidence of residual obstruction. (2,4) Anticoagulation therapy reduces the overall mortality and morbidity associated with this syndrome. However, some studies demonstrate an increased risk of residual venous obstruction in $78 \%$ of cases managed only with anticoagulation. ${ }^{(4)}$ Urschel et al. describes that only $29 \%$ of patients treated with anticoagulation reported a good or excellent outcome. ${ }^{(5)}$ There was no evidence related to the use of new oral anticoagulants for the management of upper limb thrombosis.

In cases of external compression by scaring and fibrosis the treatment needs a surgical decompression to avoid a subsequently rethrombosis. ${ }^{(6)}$ The surgical procedure should be performing 1 or 2 month after the episode.

\section{Conclusion}

In conclusion, early diagnosis and treatment of the Paget-Schroetter syndrome is critical for preventing potentially fatal complications such as pulmonary embolism. Prophylaxis is important for preventing recurrent thrombosis and for avoiding development of post-thrombotic syndrome. Paget-Schroetter syndrome should be considered a possible cause of painful swelling of the upper limb, especially significant edema, blue discoloration, and dilatation of the superficial veins in the patient's right upper limb in young, active patients who use their arms excessively.

In addition, there are few studies related with the use of new oral anticoagulants for medical management. In this case report, we use one of the new oral anticoagulants. Further clinical trials are needed to show the clinical benefits of this drug and prove an association. 


\section{References}

1. Illig KA, Doyle AJ. A comprehensive review of Paget-Schroetter syndrome. J Vasc Surg 2010 Jun;51(6):1538-47.

2. Alla VM, Natarajan N, Kaushik M, Warrier R, Nair CK. Paget-schroetter syndrome: review of pathogenesis and treatment of effort thrombosis. West J Emerg Med 2010 Sep;11(4):358-62.

3. Zell L, Kindermann W, Marschall F, Scheffler P, Gross J, Buchter A. Paget-Schroetter syndrome in sports activities--case study and literature review. Angiology 2001 May;52(5):337-42.

4. Adams JT, DeWeese JA. "Effort" thrombosis of the axillary and subclavian veins. J Trauma 1971 Nov;11(11):923-30.

5. Urschel HC Jr, Razzuk MA. Paget-Schroetter syndrome: what is the best management? Ann Thorac Surg 2000 Jun;69(6):1663-8; discussion 1668-9.

6. Beygui RE, Olcott C 4th, Dalman RL. Subclavian vein thrombosis: outcome analysis based on etiology and modality of treatment. Ann Vasc Surg 1997 May;11(3):247-55.

7. Oktar GL, Ergul EG: Paget-Schroetter syndrome. Hong Kong Med J, 2007,13: 243-245.

8. Ilhan E, Ture M, Yilmaz C, et al.: Subclavian vein thrombosis extending into the internal jugular vein: Paget-von Schroetter Syndrome. J Clin Med Res, 2009, 1: 178-180.

9. Maharaj D, Ramdass M, Perry A, et al.: Paget von Schroetter Syndrome secondary to exotic dancing: a case study. Int J Angiol, 2003, 12: 143 144.

10. Akita K, Ibukuro K, Yamaguchi K, et al.: The subclavius posticus muscle: a factor in arterial, venous or brachial plexus compression? Surg Radiol Anat, 2000, 22: 111-115.

11. Ozçakar L, Kaymak B, Turan S, et al.: Thoracic outlet syndrome, PagetSchroetter syndrome and aberrant subclavian artery in a young man. Joint Bone Spine, 2006, 73: 469-471.

12. Ozçakar L, Dönmez G, Yörübulut M, et al.: Paget-Schroetter syndrome forerunning the diagnoses of thoracic outlet syndrome and thrombophilia. Clin Appl Thromb Hemost, 2010, 16: 351-355.

13. Lewandowski A, Syska-Sumińska J, Dłuzniewski M: [Pulmonary embolism suspicion in a young female patient with the Paget-von Schrötter syndrome]. Kardiol Pol, 2008, 66: 969-971.

14. Bolcal C, Oz K, Sirin G, et al.: Paget-von Schroetter Syndrome associated with thrombophilia. Turk J Thorac Car-diovasc Surg, 2007, 15: 304-306.
Received: 16/06/2017

Accepted: 04/09/2017

Published: 15/09/2017

Disclosure and conflicts of interest:

The authors declare no conflict of interest.

\section{Corresponding author:}

Kenan Abdurrahman Kara

Mail: kenankaradoc@gmail.com 